Selcuk Journal of Agriculture and Food Sciences

http://sjafs.selcuk.edu.tr/sjafs/index

Research Article
SJAFS

(2021) $35(1), 18-23$

e-ISSN: $2458-8377$

DOI: $10.15316 /$ SJAFS.2020.223

\title{
Identifying Preferences of Red Meat Consumption by Means of Conjoint Anal- ysis
}

DAykut ÖZÜAK ${ }^{1}$, Dỉsmail KESKİN ${ }^{1 *}$

${ }^{1}$ Selcuk University, Faculty of Agriculture, Department of Animal Science, Konya, Turkey

\begin{tabular}{l}
\hline ARTICLE INFO \\
\hline Article history: \\
Received: 12.10 .2020 \\
Accepted: 17.01 .2021 \\
\hline
\end{tabular}

Edited by:

İbrahim AYTEKIN; Selcuk University, Turkey

Keywords:
Conjoint
Red meat
Preference
Orthogonal plan

\section{Keywords:}

Conjoint

Orthogonal plan \begin{abstract}
In this study, in order to identify the preferences of red meat consumption in Konya, conjoint analysis was used, which has been quite commonly used in product production and existing market studies. Preference cards used in the study were applied to 201 people. People were asked to put in order preference cards by coding as " 1 " the mostpreferrable toward they prefer the least, and the full profile method is used.

Kendall's Tau value stating representation power of the model was identified as 0.974 and Pearson's R, as 0.993 . At the end of the study, it was seen that the factors affecting red meat preferences and purchasing behaviors of the people living in Konya were purchasing place $(46.5 \%)$, sort of meat $(17.7 \%)$, purchasing way (13.0\%), fat rate of the meat purchased (12.9\%) and, finally, meat price.

As a result, it was expressed that conjoint analysis would help about which changes businesses could make in their products or services, which points they had to be dealt with product development studies, and in what direction the existing and potential customers in market could react. .
\end{abstract}

\section{Introduction}

At the present time, per capita red meat consumption is one of the most importantcriteria determining the development and welfare levels of countries (Ekinci, 2018). The cultural levels, incomes, and social life features of people are also of the most important factors determining habitual meat consumption (Kibar et al., 2019). In the countries having high socioeconomic level, it is seen that per capita rates of meat production are also high (Arisoy and Bayramoğlu, 2015). In addition, also in protecting community health against pandemics such as Covid-19, red meat consumption is important.

In Turkey, as of 2019, there are 17688139 heads of cattle, 184192 heads of water buffalo 37276050 heads of sheep, and 11205429 heads of goat in Turkey, and a total of red meat actualized as 1201470 ton (TUIK, 2019). If the population of Turkey is considered to be 82 million in 2019, per capita consumption of red meat it appears to be about $15 \mathrm{~kg}$.

\footnotetext{
*Corresponding author email: ikeskin@selcuk.edu.tr
}

For communities to be able to be nourished healthily and balanced, it is necessary to increase the production of red meat and meat products and improve their qualities. Together with increasing red meat and meat produstsconsumption as quantity, how to introduce it to consumers becomes an important issue. In such conditions, utilizing conjoint analysis, the features consumer give importance in purchasing meat can be identified.

Frequently used conjoint analysis at the present time (analysis of relationships or togetherness) is an analysis technique preferred by researchers for identifying the characteristics of consumer behaviors. Conjoint analysis enables businesses to acquire important information about the issues such as which changes they can make in their products or services; which points to deal with the studies of product development; how the existing and potential consumers in market will react to these changes; how general tendency in market will affect the product and services; how the balances in market will change, if business continues with its existing products and services or develops the new products and services; in what direction the effects of new products and services of 
rivals on consumers will be; and how pricing will reflect to market (Turanlı et al., 2013).

Conjoint analysis is used in case that some variables cannot be measured in real meaning and are expressed in the form of levels (qualitatively), in order to study the relationships between variables and levels. In conjoint analysis, there are two objectives, in which the efficiency of multi-feature product or service in identifying consumer preferences is revealed. These are identifying of preference ranking of combinations the variables and levels form (general consumption model) and testing the trueness of model potential customer prefers in making decision (individual consumption model) (Tatlıdil, 1995).

This study was carried out to identify preferences of red meat consumption by means of conjoint analysis in Konya City.

\section{Materials and Methods}

\subsection{Material}

In this study carried out to identify the red meat preferences and factors affecting purchasing behaviors of the people living in Konya, conjoint analysis was used.The material of the current study are 201 surveys applied to the red meat consumers in Konya City, Turkey

\subsection{Method}

In the study, plan cards were formed by orthogonal order for meat consumption preferences, and a specific survey containing combinations of factor levels was prepared to put in order preferences. By means of this survey, people were asked to put in order selection cards in such a way that they put in order selection card they prefer the most by coding as 1 toward that they prefer the least, and full profile method was used.

In the survey, for consumers to form preference order or rank combinations, the following questions were raised:

1) Where do you prefer to buy the meat from? (Any butcher, A certain butcher, Market/Supermarket)

2) Sort of meat you buy (Beef, sheep)

3) The way you buy the meat (Mincemeat, In small pieces, Bone in meat),

4) Fat content the meat you buy (Low-fat, Middlefat, Super-fatted),

5) The price of the meat you buy (Low, Middle, High).

During preparing orthogonal order, while the number of card is wanted to be 16 to 18 until 7 factors with 2 or 3 levels, in case that there are more factors, it was reported that using 20 cards was suitable (Yalnız and Bilen, 1997). The number of levels of the variables dealt with this study is a total selection cards containing all combinations of the levels of 3, 2, 3, 3, 3 , respectively and is $3 \times 2 \times 3 \times 3 \times 3 \times 3 \times 2=162$. However, since it will be difficult (almost impossible) for responders to rank all of these 162 cards, the amount of the variables and levels determined should be reduced. For being able to reduce the number of the variables and levels, orthogonal model should be used (Cengiz, 2009). Hence, by means of orthogonal test order that is a test order, in which only main features are considered, the number of cards that can represent 162 cards were determined as 18 original cards and 4 holdoutcards. With 18 pieces of cards prepared to be presented to the people that will participate in the survey, the rule of the minimum number of cards that is necessary to be formed was fulfilled. In addition, other than these cards, 4 pieces of simulation (holdout) cards were formed. Thus, utility predictions of 162 cards were calculated through utility obtained from 18 cards. Ranking the utility values found from largeto small, in the framework of features of each card, thus, of each product, with moving from preferences order and this ranking, purchasing behaviors of consumers were identified.

While applying conjoint analysis, it is necessary to reveal the relationships between factor levels dealt with and preference orders. The factor expected to be a linear increase between preference orders and it was defined as "linear more", linear decrease, as "linear less", and the factors whose levels are categorical, as "discrete" (Cengiz, 2009).

In the study carried out to identify habitual consumption of red meat in Konya City, for identifying sample volume, the following formula was used (Newbold, 1995; Kibar et al., 2019).

$$
n=\frac{Z^{2} p q}{d^{2}}
$$

In the formula, $\mathrm{n}$ denotes sample size; $\mathrm{p}$, probability of the desired case to occur in population $(\mathrm{p}=0.5)$; $\mathrm{q}$, probability of the undesired case to occur in population $(q=0.5) ; Z$, the value in standard normal distribution table $(Z=1.96$ for $5 \%$ ); and $d$, the largest amount of error desired $(\mathrm{d}=10 \%)$. With the formula, the minimum number of people, to whom survey will be applied, was identified as 96 but considering that questionnaires will be left blank or not will be completed, in this study, 201 participants were interviewed one to one and preference orders were formed.

\section{Results and Discussion}

In the study, consumers were asked to assign preference points or rank combinations to 22 cards (18 original cards and 4 holdoutcards) formed by means of orthogonal plan. As identifying information belonging to the people assigning preference points or asked them to rank the combinations formed, there are the data such as age, gender, marital status, educational status, the number of individual in household, and average monthly income. Some statistics belonging to these features are given in Table 3.1 or Figure 3.1-3.6. 
Table 3.1

Some statistics of the people surveyed

\begin{tabular}{llll}
\hline Variables & Variable Levels & $\mathrm{n}$ & $\%$ \\
\hline \multirow{4}{*}{ Age } & $<25$ & 42 & 20.9 \\
& $26-35$ & 65 & 32.3 \\
& $36-45$ & 48 & 23.9 \\
& $46-55$ & 37 & 18.4 \\
\multirow{2}{*}{ Sex } & $>56$ & 9 & 4.5 \\
\hline \multirow{2}{*}{ Marital Status } & Male & 116 & 57.7 \\
& Female & 85 & 42.3 \\
\hline \multirow{4}{*}{ Education Status } & Married & 108 & 53.7 \\
& Single & 93 & 46.3 \\
\hline \multirow{2}{*}{ Number of Family Members } & Primary School & 14 & 7.0 \\
& Middle School & 21 & 10.4 \\
& High School & 65 & 32.3 \\
& University & 96 & 47.8 \\
& Master/Doctorate & 5 & 2.5 \\
\hline \multirow{2}{*}{ Monthly Income } & 2 & 26 & 12.9 \\
& $>6$ & 136 & 67.7 \\
& $<2400$ & 39 & 19.4 \\
\hline
\end{tabular}

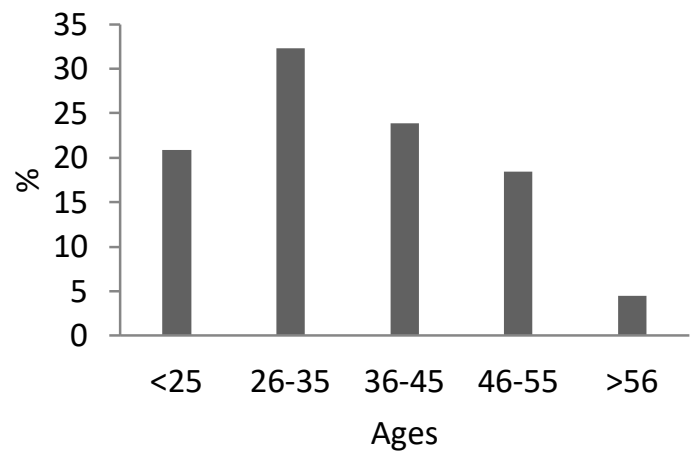

Figure 3.1

Age of the people surveyed

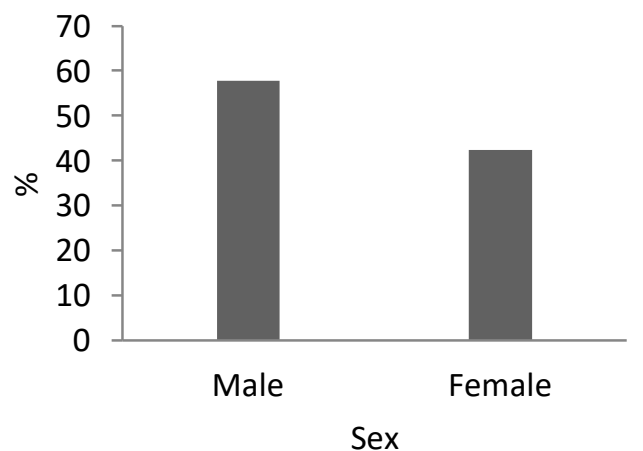

Figure 3.2

Gender of the people surveyed

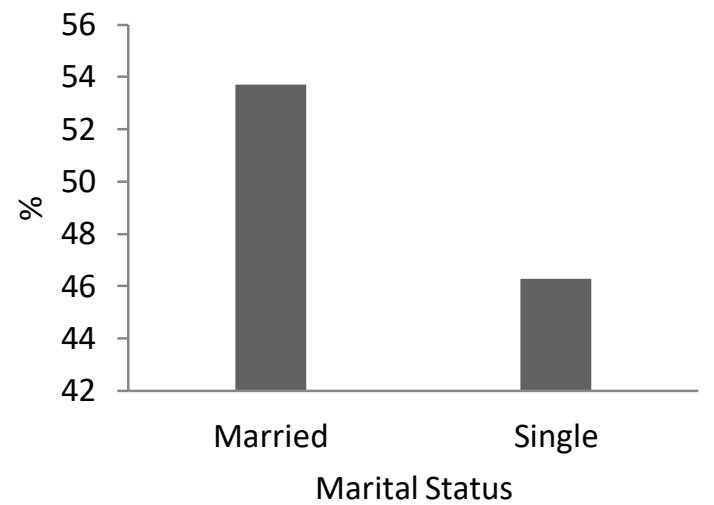

Figure 3.4

Marital status of the people surveyed

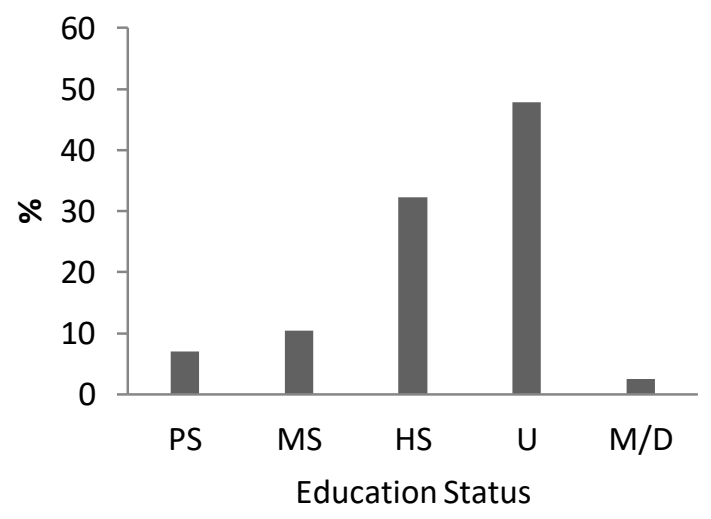

Figure 3.5

Educational status of the people surveyed

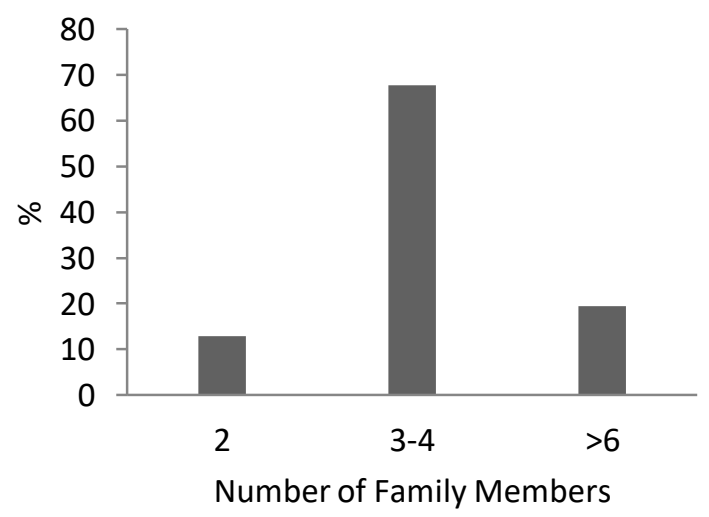

Figure 3.6

Number of family members of the people surveyed 
Table 3.2

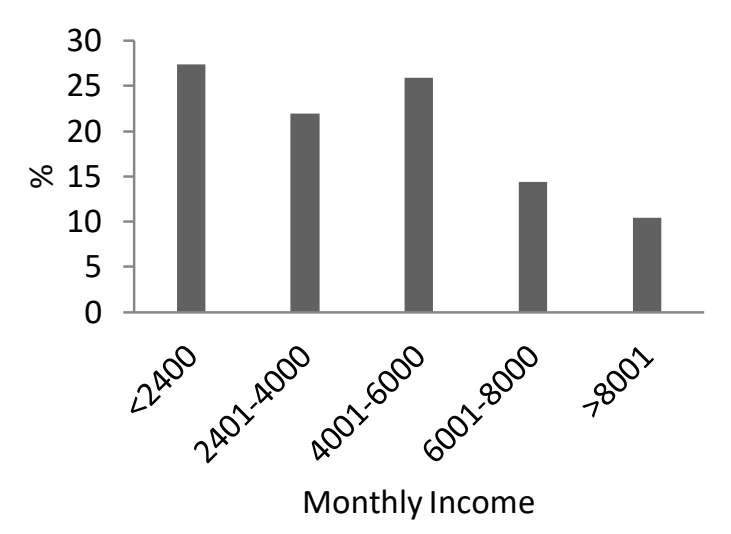

Figure 3.6

Monthly income of the people surveyed

In the study, as a result of conjoint analysis for 201 people, Kendall's Tau value stating representation power of the model was identified as 0.974 (Sig.=0.000). The model set up according to Pearson's $\mathrm{R}$ and Kendall's Tau values complies with the preferences of participants. There is $99.3 \%$ of correlation between the model set up and the results observed.

According to analysis results, it was seen that the most affecting factor red meat preference and purchasing behaviors of the people living in Konya was firstly purchasing place $(46.5 \%)$. Kibar and Mikail (2018), in the study they carried out in Siirt City, found that the factor "purchasing place" was significant for the people regularly consuming meat. For the people not regularly consuming meat, purchasing place has the least significance. With utility coefficient of 2.270 , it was seen that consumers preferred a certain butcher. This was followed by sort of meat (17.7\%). It was seen that consumers preferred beef the most (utility coefficient: 1.060). These variables are followed by purchasing way $(13.0 \%)$. In purchasing way of meat, utility coefficients were 0.247 for mincemeat and 0.250 for "in small pieces", and these were preferred in the close rate to each other. The fatcontent of meat was effective in $4^{\text {th }}$ rank $(12.9 \%)$. It was seen that the consumer preferred slow fat meat the most (utility coefficient: 0.426). It was identified that price took place in the last rank in red meat consumption preferences (9.9\%) (Table 3.2). According to the results consisting of common evaluations of all participants, an ideal combination of red meat preference formed in the form of a certain butcher beef - in small pieces meat - low fat meat - low price. The least preferred combination of red meat formed in the form of market/supermarket - sheep - bone in meat - super fatted meat - high price.
Obtained for the variables "Total Utility Coefficients" and "Proportional Significance Values"

\begin{tabular}{llll}
\hline Variables & Variable Levels & TUC & PSV \\
\hline V1 & Any butcher & -0.410 & \\
& A certain butcher & 2.270 & 46.5 \\
& Market/Supermarket & -1.850 & \\
\hline V2 & Beef & 1.060 & 17.7 \\
& Sheep & -1.060 & \\
\hline V3 & Mincemeat & 0.247 & 13.0 \\
& In small pieces & 0.250 & \\
& Bone in meat & -0.497 & \\
\hline V4 & Low-fat & 0.426 & 12.9 \\
& Middle-fat & -0.160 & \\
& Super-fat & -0.266 & \\
\hline V5 & Low & -0.298 & 9.9 \\
& Middle & -0.596 & \\
& High & -0.894 & \\
\hline
\end{tabular}

(TUC: Total Utility Coefficients, PSV: Proportional Significance Values, Where do you prefer to buy the meat from: V1, Sort of meat you buy: V2, The way you buy the meat: V3, Fat content the meat you buy: V4, The price of the meat you buy: V5)

The proportional significance values of the factors affecting red meat consumption preferences and purchasing behaviors of the people living in Konya were given in Figure 3.7.

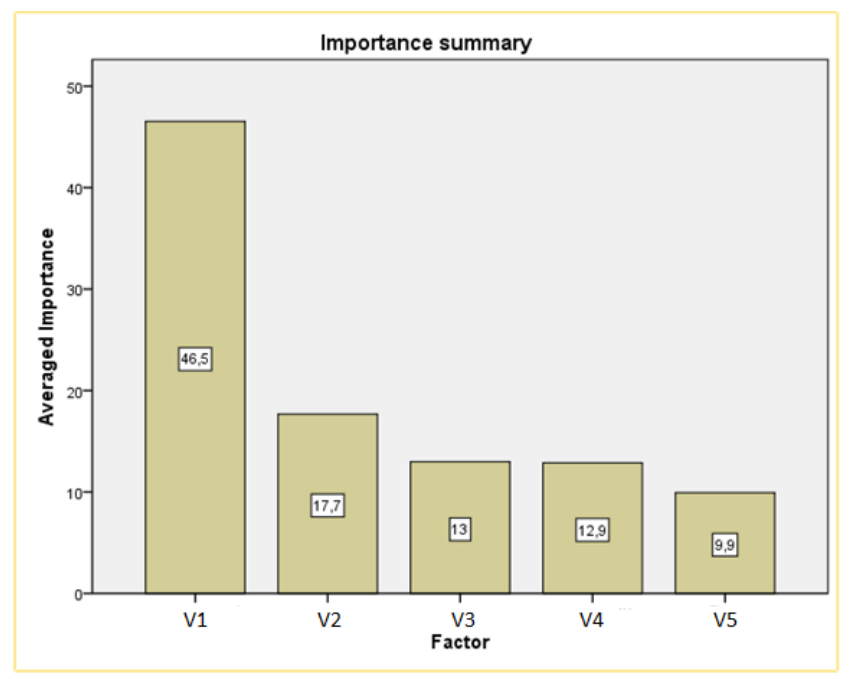

Figure 3.7

Importance rates of factors that affect red meat preference

After total utility coefficients were determined, utility scores of cards were calculated. Constant coefficient (9.375), obtained as a result of analysis, and utility coefficients of level of each variable that pass in the card were added, and utility value of card was calculated as follows:

Utility for $1^{\text {st }}$ card $=9.735+(-0.410)+(-1.060)+$ $0.250+(-0.160)+(-0.894)=7.461$

Utility for $2^{\text {nd }}$ card $=9.735+2.270+1.060+0.247+$ $(-0.266)+(-0.894)=12.152$

Utility for $12^{\text {th }}$ card $=9.735+2.270+(-1.060)+(-$ $0.497)+(-0.266)+(-0.298)=9.884$

Utility for $18^{\text {th }}$ card $=9.735+2.270+1.060+0.247+$ $0.426+(-0.894)+12.844$ 
Calculations made for the other cards are given in Table 3.3.

Table 3.3

Utility scores of all cards

\begin{tabular}{lcccccc}
\hline CN & V1 & V2 & V3 & V4 & V5 & US \\
\hline 1 & AB & Sheep & ISP & MF & H & 7.461 \\
2 & ACB & Beef & MM & SF & H & 12.152 \\
3 & ACB & Sheep & ISP & LF & M & 11.025 \\
4 & ACB & Sheep & BIM & LF & H & 5.860 \\
5 & ACB & Beef & ISP & LF & L & 9.323 \\
6 & AB & Beef & ISP & SF & H & 9.475 \\
7 & ACB & Beef & BIM & MF & L & 12.110 \\
8 & AB & Beef & BIM & LF & M & 9.718 \\
9 & M/S & Beef & ISP & SF & L & 8.631 \\
10 & M/S & Sheep & MM & SF & M & 6.210 \\
11 & M/S & Beef & BIM & MF & H & 7.394 \\
12 & ACB & Sheep & BIM & SF & L & 9.884 \\
13 & M/S & Beef & MM & MF & M & 8.436 \\
14 & AB & Sheep & MM & MF & L & 8.054 \\
15 & ACB & Beef & ISP & MF & M & 12.559 \\
16 & AB & Beef & MM & LF & L & 10.760 \\
17 & AB & Beef & BIM & SF & M & 9.026 \\
18 & ACB & Beef & MM & LF & H & 12.844 \\
\hline $19^{\mathrm{a}}$ & AB & Sheep & BIM & MF & L & 7.310 \\
$20^{\text {a }}$ & M/S & Beef & MM & SF & L & 8.628 \\
$21^{\mathrm{a}}$ & AB & Sheep & BIM & LF & M & 7.598 \\
$22^{\text {a }}$ & AB & Sheep & MM & LF & L & 8.640 \\
\hline
\end{tabular}

(CN: Card Number, L: Low, Middle: M, High: H, AB: Any butcher, ACB: A certain butcher, M/S: Market/Supermarket, ISP: In small pieces, MM: Mincemeat, BIM: Bone in meat, MF: Middle-fat, LF: Low-fat, SF: Super-fat, US: Utility Scores)

According to utility scores obtained, utility score of red meat combination the participants preferred the most became no: 18 card combination whose utility score is the highest (12.844). No: 4 card combination became red meat combination whose utility score is the lowest (5.860) and which is preferred the least (Table $3)$.

\section{Conclusion and Suggestions}

Conjoint analysis that is analysis method, in which the efficient of a product or service in identifying consumer preferences is revealed, are used to study the interrelations of the variables and levels, in case that some variables cannot be measured in real meaning and that levels are qualitatively are expressed. If a new product is wanted to be developed or studied the status of the existing product, setting out the preferences of consumers, the most desired features of product to be produced and the status of the existing product can be determined. In this analysis, in which qualitative and quantitative data can be used, generally dealing with preference (utility) function as dependent variable, the effects of a number of independent variables on this are studied.

Thanks to conjoint analysis, producers, earlier identifying the preferences and demands of consumers, can remove their worries about whether or not introducing a new product to market. In the surveys made, when many features are asked, very different demands appear. By means of this analysis, which properties of the product are so important to producer can be detected. As a result of survey administered in producers, according to the result of conjoint analysis, each card and question have different values of significance.

The people living in Konya first of all prefer a certain butcher i.e. the butcher they always do shopping, whichever sort of meat they buy. They more preferred beef compared to sheep. In meat preferences, that beef is in small pieces and low fat became a cause of preference. Price, on the contrary to that thought, was the least considered feature.

As a conclusion, conjoint analysis will help about which changes business can make in their products and services, which points to deal with their product development studies, and in which direction the existing and potential customers in market can react to these changes.

\section{References}

Arısoy, H., Bayramoğlu, Z., 2015. Consumers' Determination of Red Meat and Meat Products Purchase Behaviour - City of Ankara Sample. Turkish Journal of Agriculture - Food Science and Technology, 3(1): 28-34.

Cengiz, E., 2009. Investigation of Product Origin, Brand, Price and Quality Variables Playing a Role in Consumers' Product Choice. Atatürk UniversityJournal of Economics and Administrative Sciences, 23 (2): 155-174.

Ekinci, M.G., 2018. Red Meat Consumption. GöllerBölgesiAylıkHakemliEkonomiveKültürDergi siAyrintı, 5 (61): 21-24.

Kibar, M., Mikail, N., Yilmaz, A., 2019. Red Meat Consumption Habits and Affecting Factors in Central District of Siirt Province. Turkish Journal of Agricultural and Natural Sciences, 6(4): 720728.

Kibar M., Mikail N., 2018. Application of conjoint analysis to determine consumers' red meat preferences in Siirt province. Scientific Papers. Series D. Animal Science, LXI (1): 303-306.

Newbold, P., 1995. Statistics for Business and Economics. Prentice-Hall International, New Jersey, 867 p.

Saraçl1, S., 2004. Conjoint Analysis in Researching Customers' Preferences and an Application to Individual Retirement Account. AnadoluUniversitySocial Sciences Institute, (Master Thesis), Eskişehir. 
Tatlıdil, H., 1995. Conjoint Analysis (Unpublished Lecture Notes). HacettepeUniversity, Department of Statistics, Ankara.

Turanlı, M., Cengiz, D.T., Işık, M., 2013. Determining the Factors Affecting Newspaper Preferences with Conjoint Analysis. Istanbul University Journal of Econometrics and Statistics, 19: 1-26.
TUIK,

2019.

(http://www.tuik.gov.tr/UstMenu.do?metod=temeli st) (Date of access: 28.09.2019).

Yalnız, A., Bilen, L., 1997. Consumer Choice with Conjoint Analysis in Kasko Insurances. HazineDergisi, 8: 53-70. 